\title{
El sujeto del trauma
}

\author{
La imagen perdida | Rithy Panh | 2013
}

\section{Caroline Renard"}

\author{
LESA, EA3274, Universidad de Aix-Marsella
}

Recibido: 15 de enero 2018; 7 de abril 2018

\begin{abstract}
Resumen
La mayoría de las películas de Rihty Panh tratan las consecuencias del régimen de Pol Pot en Camboya. La imagen perdida ofrece, en 2013, un enfoque parcialmente autobiográfico, accesible a un público amplio. El cineasta utiliza pequeños muñecos de barro, tomas de archivo y la voz de un narrador para describir las atrocidades cometidas por los Jemeres rojos entre 1975 y 1979. Esta película permite analizar la cuestión de la construcción del sujeto que enfrenta un evento traumático. Su construcción en bucle conduce a materiales traumáticos de una escena a otra y el trabajo sobre la heterogeneidad de las imágenes contribuye a la inscripción del trauma en el material fílmico.
\end{abstract}

Palabras Clave: Sujeto | Trauma | Memoria | Ausencia | Alteración de lo visible | Estética y Política

The lost image

\section{Abstract}

The majority of Rithy Panh's movies focus on the aftermath of the genocidal Khmer Rouge regime in Cambodia. The Missing Picture offers in 2013, a partially autobiographical approach, accessible to a wide audience. Rithy Panh uses clay figures, archival footage, and his narration to describe the atrocities Cambodia's Khmer Rouge committed between 1975 and 1979. This movie allows to analyze the question of the construction of the subject facing a traumatic event. In a continuous loop, the narration drives the trauma's matter from a scene to the other one. Working on the diversity of images leads the trauma in the cinematic material.

Key Words: Subject | Trauma | Memory | Absence | Alteration of the visible | Aesthetic and Politics

Al igual que otros cineastas lo hicieron anteriormente (Alain Resnais o Claude Lanzmann), o de manera contemporánea (Atom Egoyan, Anne Aghion o Wang Bing más recientemente), Rithy Panh está interesado en la forma en que el cine puede abordar las cuestiones relacionadas con los crímenes contra la humanidad. Posiblemente cuando el cine se ocupa de situaciones de holocausto o exterminio, también revela algo de la relación compleja que tiene con el psicoanálisis. La imagen perdida que Rithy Panh realiza en 2013, plantea no solo la cuestión de la posibilidad de la construcción del sujeto sobre un trauma histórico sino también el del lugar de las imágenes y el imaginario en el inconsciente histórico.

Nacido en Phnom Penh en 1964, Rithy Panh tenía 11 años cuando Pol Pot tomó el poder. La película habla de los años de su infancia vividos bajo el régimen de los Jemeres Rojos. Entre los 11 y los 15 años, internado en campos de trabajos forzados, comparte la represión vivida por dos millones de camboyanos. Allí pierde a sus padres y a una parte de su familia. En 2013, casi con 50 años de edad, regresa a ese momento de su vida en una narración parcialmente autobiográfica que completa el enfoque documental de sus películas anteriores. S21, la máquina de la muerte de los Jemeres Rojos (2003) y Duch, el maestro de las forjas del infierno (2011), interrogaban la construcción de la memoria colectiva mediante imágenes de archivo y el encuentro con testigos. Si bien durante años Rithy Panh ha buscado en vano en los archivos khmer o a través de la población obtener imágenes de violencia o ejecuciones ordenadas por Pol Pot, decide crear él mismo esta imagen perdida utilizando estatuillas de arcilla y un decorado pintado.

Sin volver a los detalles de su biografía, es importante recordar que, como superviviente de los campamentos Jemer, Rithy Panh se unió en 1979 al de Mairut en Tailandia antes de llegar a Francia. En la década de 1980,

caroline.renard@univ-amu.fr 
trata de rechazar todo aquello que pudiese recordarle la pesadilla de su infancia, incluida la lengua jemer. Luego de realizar un aprendizaje en carpintería, ingresará a Idhec para dirigir un trabajo cinematográfico de memoria. "A los dieciocho años", escribe, descubro "Noche y Niebla” de Alain Resnais. Estoy sorprendido. Es igual. Está en otro lugar. Es antes que nosotros. Pero somos nosotros. $\mathrm{El}$ acercamiento con los campos de exterminio nazis es sorprendente por la identificación con una situación alejada a la de Camboya. Decir: "Está antes que nosotros. Pero somos nosotros" 1 crea un terrible efecto de repetición histórica. Un poco más allá, agrega, "No vine al cine por la gracia de Godard, Truffaut o John Ford. Vine al cine motivado por la necesidad de contar esta historia." Casi toda su obra está actualmente dedicada a Camboya.

Para comprender la especificidad de los acontecimientos de Camboya, es necesario poder diferenciar la lógica de los campos de concentración de la lógica de las políticas genocidas, incluso si la primera puede, en algunos casos, servir a la segunda. La lógica de los campos es la lógica de dejar de lado y confinar a las personas que el régimen considera que deben y pueden ser "reeducadas" mientras que la política genocida establece una organización que busca eliminar sistemáticamente a una población elegida como objetivo.

En Camboya, entre el 17 de abril de 1975 y el 7 de enero de 1979, los jemeres rojos causaron la muerte de casi dos millones de personas, aproximadamente una cuarta parte de la población. Rithy Panh habla de un "genocidio". Ahora bien, sería más exacto hablar de "politicidio". De hecho, las víctimas pertenecen al mismo grupo étnico que su verdugo y han sido en parte aniquiladas por la hambruna, la enfermedad y el agotamiento causados por el trabajo forzado que fueron obligadas a realizar. La organización de Kampuchea democrática aplicaba la tortura para obtener confesiones de sus supuestos enemigos políticos, el trabajo forzoso para su reeducación, pero no había puesto en marcha una estructura con el exclusivo propósito de exterminio.

Con una historia escrita en colaboración con Christophe Bataille y figuras de arcilla puestas en escena en decorados pintados, el realizador pone en imágenes y sonidos los acontecimientos de su infancia. Esta película se topa con las propias resistencias conmemorativas de su autor. La imagen perdida que lo atormenta es tanto la de la catástrofe que nada pudo evitar, una imagen reprimida del exterminio de su familia y una gran parte de la población camboyana, como la imagen deseada que podría potencialmente reparar el dolor que le da origen. Es directamente la relación entre el trauma, la represión y la imagen restaurativa y, por lo tanto, entre el cine y el psicoanálisis, aquello que esta película nos permite explorar.

En una entrevista, Rithy Panh explica: "En esta película, lo que me interesó fue hablar sobre la relación entre mí y el niño que era, y resultó bien con, por un lado, una voz muy seria en off para el adulto que soy, y por el otro, una estatuilla expresiva para el niño que era. Era un niño fuerte e instintivo. Es él quien vela hoy sobre el adulto, le da una razón de ser, una razón para expresarse. Da el significado de la vida, de la historia. Se creó una relación entre el trauma y la imagen restaurativa. No puedo explicarlo yo mismo, pero creo que, nuevamente, toca algo bumano en general y que otros pueden aprovecharlo." ${ }^{3}$ La lógica de la película es, de hecho, compartir la experiencia vivida y la posible identificación con estas estatuillas coloridas. Inanimadas y, a pesar de eso, expresivas, ellas permiten a las espectadoras y a los espectadores identificarse fácilmente con el niño Rithy Panh y sentir el desaliento y el dolor frente a la opresión y a las sucesivas desapariciones de sus parientes. El muñeco del niño asociado con la voz en off del hombre adulto que observa y comenta sobre su propia infancia construye un tema cinematográfico complejo.

Me gustaría volver a la noción de "sujeto". Esta palabra interdisciplinaria y polisémica está cargada con una historia que pasa por la filosofía, la lingüística y el psicoanálisis. Con la Arqueología del sujeto, ${ }^{4}$ el filósofo Alain de Libera propone un camino para establecer una arqueología filosófica de esta noción, en el sentido de subjetividad reflexiva o de persona humana individual. De Libéra retoma la tesis de Martin Heidegger, parcialmente retomada por Jacques Lacan, de una invención cartesiana del sujeto como "yo pensante sustancial". "El sujeto nace, nos asegura Heidegger, en cierta configuración, una cierta 'época' de la historia del Ser. Murió, Foucault lo proclamó, a comienzos de la década de 1960, al mismo tiempo que el Hombre, antes de renacer para nosotros, parece, en una especie de retorno a través de la metafísica reprimida, disfrazado de "autocuidado". ${ }^{5}$

Alain de Libera también observa que la historia del sujeto no puede rastrearse siguiendo este camino lineal. Las propuestas de Heidegger y Foucault deben ser repensadas, teniendo también en cuenta la contribución de la Edad Media. De Libera analiza la gestación de esta noción y constata que antes de ser subjetiva, es decir, en relación con la experiencia de pensamiento de la persona humana, la sustancia, en el sentido de la primera existencia real, ha sido en primer lugar, para la filosofía medie- 
val heredera de los conceptos de Aristóteles, un sujeto (subiectum, Subiectität), es decir, "aquello que sostiene o aquello a lo cual informan una forma, una cualidad, un estado, un atributo, ya sea de manera intrínseca o extrínsecamente, esencial o accidental. En este sentido, toda existencia sustancial requiere un sujeto que sea el substrato material, formal y lógico de las propiedades reales que son la causa y el factor de su existencia y de sus transformaciones". ${ }^{6}$

En la imagen perdida, la construcción del tema fílmico pasa por un trabajo extremadamente rico en materias. La película está basada en un sustrato material de alta densidad. Mezcla escenas animadas, con imágenes de archivos oficiales o de aficionados, colores o blanco y negro, tomas filmadas por el realizador en el presente o planos que muestran las manos de un artista que talla la tierra o dibuja decorados. La escena de apertura de la película nos confronta inmediatamente con esta desmultiplicación de materias de la expresión. Los primeros planos describen un stock de películas de cine abandonadas y dañadas por el tiempo. Manipulado por las manos de un operador invisible, el carrete deja aparecer fotogramas de un espectáculo de danza tradicional. En la imagen siguiente, una imagen en color restaurada muestra a una bailarina de los años 70 haciendo en cámara lenta gestos de extrema gracia antes de que un fundido a negro revele el título de la película de Rithy Panh. Es entonces cuando imágenes de olas vienen a sumergir la cámara y a golpear repetidamente la lente mientras que, en off, una voz murmura: "En el medio de la vida, la infancia regresa. Es un agua dulce y amarga. Mi infancia, la busco como una imagen perdida, o más bien es ella quien me reclama (...) el recuerdo está abí, me golpea en las sienes, me gustaría espantarlo". Luego, seis tomas describen la creación de una estatuilla de tierra de la cual la voz en off nos informa que es una representación del padre del realizador. Finalmente, un travelling sobre un decorado de maquetas apoyadas sobre arena presenta otras estatuillas que serán los personajes de la película, miembros de la familia del director. El montaje asocia lugares, épocas y objetos fragmentados y de apariencia heterogénea. La banda sonora da a este conjunto su unidad. Por lo tanto, los objetos filmados como la materia película, agua o arcilla tienen una carga subjetiva que se refiere tanto al cine, al tiempo, al trabajo de los cuerpos o de la mano sobre la materia y a la infancia del cineasta o a sus recuerdos.

El trabajo de análisis fílmico muestra que el cine (en el sentido de entidad que atraviesa las películas, potencia virtual a la que dan una sustancia) requiere precisamente un sujeto, en el sentido medieval de subiectum, es decir, un "un sustrato material, formal y lógico de propiedades reales que son causa y factor de su existencia y de sus transformaciones". El análisis de la película es lo que atestigua este trabajo de materialidad en el cine. Esta materialidad es la del soporte fílmico, también es la de su forma la que concierne al encuadre, el montaje, la intensidad sonora y luminosa, la colorimetría, el ritmo; finalmente, es también la de la lógica cinematográfica, ya sea figurativa, enunciadora o narrativa. Esta primera escena muestra en menos de tres minutos cuán sensible es Rithy Panh a la materialidad de las imágenes y cómo esta materialidad puede resolver los problemas figurativos que aquí están presentes en la represión y en la violencia de la memoria de retorno. Los rollos de bobinas de película son a la vez el recuerdo dañado de la historia del cine camboyano y su borrado, mientras que las olas son la inscripción física de la memoria que golpea las sienes del autor y que le gustaría espantar. De esta forma, se crea un sujeto fílmico que combina materias y contenidos de la expresión, sujeto de la película y sujeto realizador.

Daniel Arasse analiza y describe la figura del "sujeto en el cuadro". ' Con esta expresión, se refiere a la forma en que un artista está presente en su obra a través de marcas estilísticas, recurrencias temáticas o formales. Con ambigüedad deliberada, se refiere por "sujeto" tanto al artista, a lo que representa el trabajo y a sus destinatarios. Le interesa que, el yo íntimo del pintor, aparezca en la pintura. Para el cine, esta cuestión del "sujeto en la película” se complica aún más por la dimensión colectiva de los proyectos cinematográficos. Rithy Panh suma a esta complejidad al poner a distancia la dimensión autobiográfica de su película. Durante mucho tiempo discreto en lo que a su recorrido personal respecta, solo acepta en 2012 una especie de pasaje autobiográfico a través de su encuentro con su editor, el escritor Christophe Bataille. Para comenzar, después de una estancia en Phnom Penh, trabajan juntos para escribir La eliminación. ${ }^{8}$ El realizador le cuenta a su amigo episodios de su vida y le confía la escritura. De esta manera, explica Christophe Bataille, "trabajé durante cinco meses. Puse colores, sudor... Lo que Rithy me contó sobre la muerte de su padre se resumía a cinco líneas. Hice de jefe decorador, poniendo madera, animales y angustia...". La historia de la vida, por la palabra y la puesta en palabras, pasa así de un tema a otro. Pero el cineasta rechaza inicialmente el resultado y, en particular, la parte biográfica "Le tomó tres meses leer el texto y su única respuesta fue: 'Retírame. Suprime la infancia." Rithy Panh está familiarizado con el trabajo 
de investigación y producción documental, pero rechaza el lugar autobiográfico de su pensamiento. Su editor y amigo trabaja para convencerlo de que mantenga la historia de su vida en el texto. "Le dije, 'No estoy para nada de acuerdo. Si quieres mantener solo a Duch, será su victoria. $Y$ además, será sin mí. Te devuelvo las páginas $y$ te arreglas solo. La pelea entre nosotros, por mensajes de texto y correo electrónico, duró más de dos años. Fue una buena pelea. También se podría hacer un texto de la bistoria del manuscrito, que contó con ciento treinta versiones."

Un año después de ceder a la publicación de este libro, Rithy Panh realisa La imagen perdida. La voz que habla en primera persona del singular en la película también fue escrita por Christophe Bataille con un "Yo" movido. Battle dice "Yo" en lugar de Rithy Panh como si la narración personal pudiera ser llevada por alguien más que uno mismo. La voz que escuchamos tiene un ligero acento, no es la del realizador sino la del actor franco-camboyano Randal Douc. Esta historia escrita por otro en primera persona también es pronunciada por otro. De esta manera, mientras está en todas partes “en” la película, el cineasta se ubica a una distancia máxima. La forma elegida no es a pesar de eso la de la autoficción. El "sujeto en la película" es objeto de una serie de desplazamientos, transformaciones y de puestas en redes que le dan un grosor particular.

También se debe enfatizar que la estructura narrativa y visual de la narración se basa en un trabajo de repeticiones incesantes. El cineasta no solo regresa a este inquietante tema de una película a otra en su filmografía, sino que la repetición trabaja también la estructura misma de La imagen perdida. La voz en off anuncia, desde el comienzo, el regreso del motivo de la infancia en el medio de la vida. Este motivo regresa de una secuencia a la siguiente, se elabora en la recuperación y se dibuja gradualmente mediante sucesivas acumulaciones para producir una especie de efecto de elaboración cinematográfica. "Para describir la estructura de mis películas", dice Rithy Panh, "me gusta pensar en la imagen de una rueda: ella gira sobre si misma y avanzamos de todos modos". Un registro detallado de las secuencias permite ubicar todos los motivos (visuales o temáticos, formales o narrativos) que, como el de la infancia, se enunciarán rápidamente, retomados luego, desarrollados y se comentarán a medida que transcurre la película. Esta lógica de la rueda que "gira sobre sí misma" justifica la fragmentación de la narración y asegura un principio de avance por asociación de ideas, palabras, imágenes.
La historia parece a veces más cercana a la lógica del sueño que a la del documental. Su recorrido sigue los meandros de la memoria del narrador, se desvía, repite preguntas, desplaza sensaciones. El espectador entiende que repetir es retomar y trabajar incesantemente la misma materia. En este caso, el trauma. La película repite la desaparición del padre que se deja morir de hambre en el campo de reeducación en el que está preso, repite la muerte del hermano, de la madre, del hijo menor y de millones de prisioneros. Es imposible decir cuál es el momento traumático, ni siquiera es posible definir exactamente la naturaleza del trauma para el sujeto de la película. Pero el trauma es trabajado por la película como la arcilla por el escultor, es decir como uno de los elementos constitutivos y estructurantes del sujeto que lo repite. Saber que para los especialistas en psicoanálisis "el trauma es, sin duda, uno de los conceptos más indecisos de los más equívocos, y probablemente de los más enigmáticos" confirma la intuición transmitida por la película. Claude Le Guen afirma que esta esquivez del trauma "se debe a la ambigüedad de sus confluencias ubicadas en el encuentro del adentro y del afuera, la dinámica de exceso, de quiebre y de pérdida, a su función de alarma y protección como a su poder de ruptura. Esta cita parece describir el funcionamiento de la película de Rithy Panh que realmente hace jugar juntos el adentro (la vida interior del personaje) y el afuera (su vida familiar y su inscripción social y política), el exceso (las situaciones de privación extrema o violencia extrema), la ruptura (la llegada al poder de los Jemeres Rojos) y la pérdida (la sucesión de duelos). El Guen agrega que el trauma es el "agente de una realidad cuyo poder y cuya fuente siguen siendo inciertos, (...) tiene la brutalidad de la evidencia, como la evanescencia de lo aleatorio...". ${ }^{10}$ Rithy Panh traduce esta paradoja de la brutalidad y de la evanescencia del trauma al construir su película en, o, desde la ausencia, es decir, en la imagen perdida.

Quizás esto es precisamente lo que explica su decisión de no animar a estas estatuillas: "No debemos transformar lo que vivi, lo que los camboyanos han vivido. Tomen la idea de muñecos. Son personajes espeluznantes $y$ congelados, que no hablan, durante una hora y media. Hoy, con la moda del 3D, podría haber tenido la tentación de hacer una caricatura. Pero la fuerza de estas estatuillas es precisamente su inmovilidad" ${ }^{11}$ Las figuras inanimadas, esculpidas por Sarith Mang, le permiten evocar el alma de los seres que ha amado y su sufrimiento. "Aquellos que como nosotros han atravesado estas pruebas han muerto una vez. Somos sobrevivientes Re- 
vivimos, pero con una parte de muerte. ¿ Cómo hablar de esta muerte en nosotros? Es por eso que elegí no animar estas figuras. Estos personajes congelados en arcilla son más fuertes a veces que los archivos o imágenes filmadas de propaganda" ${ }^{12}$ Por lo tanto, hay un poder particular de esta elección estética de la inmovilidad de los muñecos que debe estar ligada al uso de imágenes de archivo. Dos momentos en la película atestiguan particularmente la forma en que una imagen puede causar un trauma en el curso de una vida o en el de la historia.

Ubicadas respectivamente en el primer y el último cuarto de la película, estas dos escenas citan imágenes de archivo. En la primera, Rithy Panh recuerda que, por la noche, en el campamento, les contaba historias a sus camaradas y, en particular, un día, la de la misión Apolo 11. Un plano describe la maqueta reducida del hogar de la infancia en el que toda su familia se había reunido en 1969 para ver en televisión este evento histórico. En la maqueta de madera, frente a las estatuillas que se enfrentan a la pantalla, las imágenes de televisión del lanzamiento del cohete aparecen incrustadas. Luego esta imagen invade todo el cuadro y permite ver a los astronautas, la superficie de la luna, la huella de Neil Armstrong. La voz adulta en off nos informa que cuando era niño, el cineasta también había soñado con caminar sobre la luna. El hecho de relatar a sus camaradas el recuerdo de estas imágenes vistas unos años antes, provoca una discusión en el campamento. A la pregunta de quiénes son estos hombres que caminan en la luna, el que responde "estadounidenses" es asesinado porque desde el punto de vista jemer, el proyecto del gran salto "no está en la propaganda capitalista. Él está aquí para nosotros que tenemos hambre". En algunos planos descriptivos que parecen muy anodinos, y con una cita breve de televisión que presenta un motivo literalmente extraño, y absolutamente heterogéneo para el resto de la historia, la película muestra cómo los Jemeres rechazaron las imágenes que no respondían a su ideología y cómo han tratado de transformarlas para hacer que se ajusten a sus deseos. Las imágenes son, por lo tanto, también objetos de violencia. Son espacios de puesta en crisis potencial que son respondidos por una violencia hecha a aquellos que las hacen o a quienes difunden su existencia.

La otra escena, ubicada 25 minutos antes del final de la película, es un poco menos autobiográfica. Rithy Panh combina dos tipos de imágenes de archivo. En primer lugar, imágenes de propaganda de las cuales él subraya que no faltan. En este caso, se trata de imágenes de la obra en tiempo rápido, imágenes de abundancias, de cultivos, de bolsas de arroz y consignas gloriosas que valorizan la elección de gobernantes, pero que son contradichas por la voz en off recordando la realidad de años de hambruna. Rithy Panh sube luego una escena de una reunión política. Pol Pot toma la palabra para hablarles a los jóvenes. Estas imágenes fueron filmadas por su camarógrafo, Ang Sarum. Sin embargo, su calidad técnica es mediocre, están ligeramente veladas. “¿Por qué este velo?”, se pregunta la voz en off. " $¿$ Es esto un error técnico? ¿ o quiere mostrar a los niños en harapos, revelarle al hermano número uno el estado de su país? El camarógrafo es torturado y ejecutado. Su cuerpo desaparece. Su historia desaparece. Pero no esta película". Al exponer estas imágenes, Rithy Panh recuerda cómo se impuso el silencio al cine y a la población. ¿El operador buscó un medio figurativo para contar la realidad sin mostrar que él lo sabía? Esta imagen temblorosa y borrosa provoca un efecto de desfiguración de lo visible. Ang Sarum logra, con los medios del cine, significar que algo es disfuncional en lo que él da para ver. Filma lo que le pidió su patrocinador, pero logra poner en crisis las formas visuales para sacar lo real del orden establecido. Al destilar así un ligero disturbio, produce en los líderes tal ansiedad que pone su vida en peligro.

Estas dos series de imágenes: la de la televisión estadounidense y la del operador jemer parecen muy lejanas. Una introduce un motivo ajeno a la historia (el viaje al espacio), la otra una alteración de lo visible (el desenfoque). Ambas conducen a una sentencia de muerte. A los ojos del poder, representan una forma de traición a la ideología existente. En la película de Rithy Panh, abren una dimensión del espacio cinematográfico cuyo alcance también es documental. La presencia de estatuillas de arcilla que representan en un caso a los televidentes de 1969 y en el otro al operador Ang Sarum, introduce la cuestión de la recepción de imágenes y la de su fabricación. El recordatorio regular de la existencia de este espacio profílmico crea un fuera de campo que es el de la producción y distribución de películas. Este espacio es potencialmente un lugar de manipulación de la realidad marcado por una ideología siendo a la vez un espacio de creación íntima y subjetiva. Los planos sobre las manos del alfarero, los planos sobre los operadores de películas de propaganda, la evocación del trabajo de realizadores de ficción, la evocación de Ang Sarum y la misma presencia del realizador Rithy Panh hacen referencia de manera regular al conflicto entre la imagen y el poder. Tanto para Rithy Panh, como para Ang Sarum, el objetivo es producir una imagen "a pesar de todo", ${ }^{13}$ es decir, a pesar 
del horror al cual se refiere, a pesar de lo insoportable que designa, a pesar del riesgo al que se somete aquel que la realiza. Aquí, Rithy Panh nos recuerda que cuando para los líderes el desafío es silenciar la realidad, el riesgo es vital.

$\mathrm{Al}$ igual que los motivos tomados de una escena a otra y los planos del oleaje, estos motivos cinematográficos de gran heterogeneidad, demuestran que en la "película no está en juego el regreso repentino, al presente, del evento traumático, pero sí lo está la elaboración de la memoria tratando de darle forma" ${ }^{14}$ Esta elaboración implica un trabajo de repetición, de investigación, de interrogación y de una nueva repetición. Hemos visto la difícil inscripción de la subjetividad para Rithy Panh y cuestionamos la forma en que su cine logra objetivarlo mediante un uso particular del "yo" y de la voz. Produce así un espacio verdaderamente intersubjetivo que no se limita a la yuxtaposición de subjetividades, al retorno sobre uno mismo o al reconocimiento del mismo. El concepto de sujeto que nos ha interesado aquí probablemente no está ni dentro de los límites del Yo, ni en el del Cogito cartesiano. Atraviesa la película, como atraviesa al cine y a los seres, e irriga la dimensión artística y estética como la dimensión política de nuestra relación con el mundo. Este sujeto no es un objeto con contornos claros, no es posible de atrapar, ni fijarlo para observarlo, pero el cine puede ayudarnos a acercarnos a él para hablar sobre él.

\section{Traducción: Sergio Peralta}

1 La eliminación de Rithy Panh con Christophe Bataille, éd Grasset, 2011, p. 250.

$2 \quad$ Ibidem

3 Entrevista con Frédéric Strauss "La imagen ausente, la voz de la infancia en el barullo de Cannes”, Télérama, 20 de mayo de 2013.

$4 \quad$ Alain de Libéra, Arqueología del sujeto, Tomo 1, Nacimiento del sujeto, ed. Vrin, Paris, 2007.

$5 \quad$ Alain de Libera, op. cit. p. 18.

6 Emmanuel Brassat, “Alain de Libera, Arqueología del sujeto”, Essaim 2009/1 (n² 22), p. 105.

7 Daniel Arasse, El Sujeto en el cuadro Ensayos de iconografia analítica, coll. Ideas e investigaciones, Flammarion, Paris, 1997.

8 Rithy Panh con Christophe Bataille, Laeliminación, éd. Grasset, 2012, 336 pp.

9 Christophe Bataille, Entrevistado por François Ekchajzer, Télérama, publicación del 9/10/2013 citado en la carpeta de prensa de La imagen Perdida, Stéphane Bou, p.20.

10 Claude Le Guen en el prefacio del libro de Claude Janin, Figuras et destinos del traumatismo, Paris, P.U.F., 1996.

11 Entrevistado por Florence Colombani, Le Point, publicación del 24/10/2015.

12 Entrevistado por Jean Claude Raspiengas, La Croix, publicación del 08/10/2013.

13 Georges Didid-Huberman, Imagenes a pesar de todo, ed. de Minuit, 2004.

14 Sylvie Rollet, Una ética de la mirada, El cine frente a la Catastrofe, Paris, ed. Herman, p. 232 